\title{
Soil Moisture: An Essential Climate Variable in Indian Monsoon Regime
}

\author{
Abhishek Lodh ${ }^{1}$, Somnath Jha ${ }^{1}$, Ramesh Raghava ${ }^{1}$ \\ ${ }^{I}$ Centre for Atmospheric Sciences, Indian Institute of Technology Delhi, Hauz Khas, New \\ Delhi-110016, India
}

\begin{abstract}
Soil moisture as an essential climate variable is studied using regional climate model and has been assessed over Indian climatic zones in Indian monsoon regime. NCEP/NCAR Reanalysis Project 2 data from 1985-1995 are used as boundary conditions to a regional climate model. The model is run on JJAS seasonal scale and analysis is only for the JJAS season each year. Strong positive feedback over mainlands of India and negative feedback over peninsular India has been witnessed. Empirical Orthogonal function (1) of model rainfall is able to capture the prime JJAS monsoon regions over India with loading of same positive sign.
\end{abstract}

Key Words: Soil Moisture, Precipitation, Evapotranspiration, Feedback, empirical orthogonal functions

\section{Introduction}

\section{(a) Motivation}

For simulation and prediction of Indian summer monsoon rainfall, both on short scale and medium range forecast, proper study and analysis of atmosphere - land interactions and analysing the role of model soil moisture, as an essential climate variable over Indian monsoon domain is important. The forcings associated with soil moisture, land-surface, boundary layer fluxes are quite complex. Various theories and thoughts exist in studying soil moisture precipitation feedback, the effects and cause of this feedback or coupling phenomenon. Better understanding (and quantification) of the soil moisture relevant processes would significantly help reduce uncertainties in future-climate scenarios, in particular, climate variability, extreme events, ecosystem and agricultural impacts 
(Seneviratne et al. 2010). The vegetation appears to be the climatic response of intermaintenance of soil moisture and precipitation and, in turn, becomes significantly active part of this inter-play. Soil moisture responds to precipitation variability but also affects precipitation through evaporation. Spatial and temporal variation of soil moisture can be a source of water for atmosphere through processes leading to evapotranspiration from land which include mainly plant transpiration and bare soil evaporation, especially in the transition zones (Seneviratne et al. 2010). Intense hotspots of coupling between soil moisture and precipitation appear in the transition zones between dry and wet climates aided by boundary layer instability (Koster et al. 2004) especially over mainlands of India (Lodh 2011). The Indian summer monsoon from June to September (JJAS), starts with dry climate and progresses to wet climate, and soil moisture precipitation feedback also follow the same trend (Lodh 2013). During wet climate, soil moisture is plenty and evaporation is controlled by atmospheric demand, whereas in dry climates i.e. before rainy season the variations in evaporation are too small to affect precipitation. Between these extremes, evaporation is large enough to influence precipitation, but the magnitude still depends on the availability of soil moisture. Hence, central India, Indo-Gangetic plains and northwestern province i.e. regions lying interior of Indian subcontinent (Koster et al. 2004) which constitute arid and semi-arid regions of India, is an interesting case to study land-atmosphere feedbacks on a seasonal scale in climate change scenario. In the atmospheric boundary layer exchange of heat, moisture and momentum fluxes within land surface affects weather and climate. Recently, Taylor et al. 2012 has also concluded that afternoon rainfall is more likely to happen over drier soil than over wet soil, signifying the role of land surface processes in occurrence of precipitation of land regions which are far away from coastal areas. 


\section{(b) Focus of paper}

Many research efforts are ongoing in basic understanding of soil water content over space and time. Soil moisture is a fundamental quantity to understand land - atmosphere interactions. The goal of this paper is a preliminary stepping-stone towards the same efforts and hence, to study the role of RegCM4 model soil moisture (upper layer) as an essential climate variable over India and hence, to assess soil moisture precipitation climatic feedback (Koster et al 2004) over India on seasonal scale in Indian monsoon regime. The feedback is studied using soil moisture, precipitation, evapotranspiration and surface temperature data from regional climate model RegCM4.0, and observations as well. The GLACE team considered results from 12 AGCM groups (Koster et al. 2005), whereas our study is trying to analyze the soil moisture-precipitation coupling using regional climate model simulations.

\section{Methodology}

\subsection{Model Description}

Regional Climate models system with higher spatial and temporal resolutions, when driven by GCMs lateral boundary conditions with accurate larger scales adds value at regional scale to climate statistics. The RegCM4 model used in this study, successfully simulate Indian summer monsoon circulation features and rainfall (Lodh 2011). RegCMs are the hydrostatic, compressible, sigma- $\mathrm{p}$ vertical coordinate model run on an Arakawa B-grid in which wind and thermo dynamical field variables [e.g., zonal (u), meridional (v), vertical $(\omega)$ wind velocities, Temperature $(T)$, relative humidity $(q)$ for upper air, surface pressure $(P)$, mean sea-level pressure] are horizontally staggered. For more model details, refer Giorgi, et al. 2012 and Giorgi 2011 RegCM4 User Manual. 


\subsection{Experimental setup and data used as boundary condition to RCM}

In the model integration, RegCM4 was run at approximately 90-km horizontal resolution with Normal Mercator map projection with 18 vertical levels in the atmosphere (sigma coordinate) and model domain is from $40^{\circ} \mathrm{E}-130^{\circ} \mathrm{E}, 0^{\circ}-40^{\circ} \mathrm{N}$ to include all the significant geographical features of the Indian Summer Monsoon region. The time step of model integration is 60 seconds. The model is run seasonally from 00GMT of $1^{\text {st }}$ April to 24 GMT of $31^{\text {st }}$ October of every year from 1985 to 1995 . The analysis is, however, confined for Indian summer monsoon period i.e. JJAS season. The initial two months of model run are kept as spin-up time for the model. The physical parameterization schemes employed in the seasonal JJAS model runs include:

(i) NCAR Community Climate Model version 3 (CCM3, Kiehl et al. 1996) radiative transfer package

(ii) Holtslag et al. (1990) boundary layer scheme

(iii) Cumulus cloud scheme of Grell (1993) with Fritsch and Chappell (1980) closure

(iv) SUBEX moisture flux scheme by Pal et al. (2000)

(v) Ocean flux scheme by Zeng et al. (1998).

Indian summer monsoon (JJAS) is best represented by the chosen configuration (Lodh 2011). The lateral and lower boundary conditions for ground temperature $\left(T_{g}\right)$, surface pressure $\left(p_{s}\right)$, sea surface temperature (SST) (except for soil moisture) were provided by the National Centers for Environmental Prediction, NCEP-DOE AMIP-II Reanalysis (R-2) (Kanamitsu et al. 2002) 6-hourly data and Reynolds weekly sea surface temperature (SST) (Reynolds et al. 2002) respectively. In the model's modeling system, the terrestrial variables including elevation, land use and sea surface temperature and three-dimensional isobaric 
meteorological data are horizontally interpolated from a latitude-longitude mesh to a highresolution domain. Vertical interpolation from pressure levels to the $\sigma$ coordinate system of the model is also performed. Sigma $(\sigma)$ surfaces near the ground closely follow the terrain, and the higher-level $\sigma$ surfaces tend to approximate isobaric surfaces. For this study, land surface parameterization scheme, the Bio-sphere Atmosphere Transfer scheme (BATS) was coupled with the model RegCM4.0. The BATS vegetation scheme coupled to RegCM4 has a vegetation layer, a snow layer, and a surface soil layer, $10 \mathrm{~cm}$ thick (Dickinson et al. 1993).

\section{Results And Discussion}

\subsection{Land - Atmosphere coupling in the RCM seasonal run (Indian monsoon domain)}

From the analysis of results from several main features of land-atmosphere coupling particularly soil moisture-precipitation climatic feedback can be identified. The correlation between $2 \mathrm{~m}$ - surface temperature and evapotranspiration designated as $\rho(\mathrm{E}, \mathrm{T})$, are shown in Figure 1(a). This correlation measures soil moisture-temperature coupling. Positivity and negativity of this correlation explains evapotranspiration to be energy and soil moisture limited respectively (Seneviratne et al. 2010). Observing Figure 1(a), negative correlation between evapotranspiration and temperature is seen over grid cells belonging to central India and northwestern regions of India. Positive correlation is seen over narrow belt along the Indo-Gangetic plains, Trans- Gangetic West Bengal and peninsular India. Over the oceans, the relationship is clear that evaporation and temperature are positively correlated (See figure 1(a)). The identical configurations of $\rho(S M, T)$ and $\rho(E, T)$ in figure $1(a, b)$ over Central India is due to top layer interaction of the atmosphere with similar residues of soil moisture 
and evapotranspiration. In comparison to Figure 1(a), Figure 1(b) captures the spatial correlation, $\rho(\mathrm{SM}, \mathrm{T})$ between soil moisture $(\mathrm{mm})$ and temperature $(\mathrm{K})$ for 1985 - 1995, JJAS season, and clearly shows negative correlation also over Western Ghats region, which is adjacent to the Arabian Sea, entire belt of Himalayas, Trans-Gangetic West Bengal.

\subsection{Empirical Orthogonal functions of RCM rainfall and soil moisture}

The empirical orthogonal functions are spatial patterns that are empirically derived basis functions. The lower order EOFs are also interpreted as natural modes of variation of observed system $^{1}$ (Kripalani et al. 1995). Hence, the spatial structure of the dominant components is studied by performing an empirical orthogonal function (EOF) analysis of monthly precipitation values of RegCM4.0 model precipitation and soil moisture. The original purpose of EOFs was to reduce the large number of variables of the original data to a few variables, but without compromising much of the variance. In this study, the empirical orthogonal functions i.e. eofs are calculated using UV-CDAT. EOF 1 of model precipitation strongly resembles pattern of maximum rainfall regions during JJAS season along the Western Ghats, foothills of Himalaya, Indo-Gangetic plains, Arabian Sea and Bay-of-Bengal. The precipitation eof values are ranging between 0 to 0.06 over the land regions of Indian subcontinent (see figure 2a), with maxima over Western Ghats and Arakan region of Myanmar. The EOF1 pattern of model soil moisture also captures the eofs values in the range from 0 to 0.05 are ranging over the mainlands of India (see figure 2b). Hence, EOF1 of model precipitation and soil moisture are of same positive sign over mainlands of India with maximum loading over Western Ghats region, agreeing with results from Kulkarni et al. 1992 (India region) and Kripalani et al. 1995 (Bangladesh region). More studies are ongoing.

\footnotetext{
${ }^{1}$ ajdawson.g ithub.io/eof2/eofs.html (EOF Analysis - eof2 1.5.1 documentation)
} 


\section{Conclusion and Future Scope of the Study}

Our study agrees with the GLACE experiment results (Koster et al. 2005) that in seasonal runs of climate model simulations, during JJAS season, South Asia (especially north-western regions of Indian subcontinent) is a region where soil moisture is an essential climate variable and a region of hot spot where soil moisture-precipitation feedback takes place. This is because of negative correlation between evapotranspiration and $2 \mathrm{~m}$ temperature over mainlands of India (Central India, Indo-Gangetic Plains, North-western India) far away from Arabian Sea and Bay of Bengal. Hence, through our study using seasonal climate simulations we confirm that using simple diagnostic parameters like $\rho(\mathrm{SM}$, T) and $\rho(\mathrm{E}, \mathrm{T})$, soil moisture-precipitation feedbacks over inlands are more than over peninsular and southern parts of India confirming recent AGCM studies (Koster et al. 2004). Also, the parameter $\rho(\mathrm{SM}, \mathrm{T})$ can also be used as a substitute diagnostic parameter to find and confirm out the regions of land atmosphere coupling (More evaluations on different time scales needs to be done). From the EOF analysis of model precipitation and soil moisture, the spatial plots variance is captured along the west coast of India and Arakan mountain regions of Myanmar. These are also the regions of high rainfall during the JJAS season. More EOF analysis of meteorological variables associated with land-surface processes is required to capture active synoptic scale interaction between cumulus rainfall variation and soil moisture variation. It will also be interesting to study the nature of land atmosphere coupling in satellite derived soil moisture products. In order to reach a conclusion, research and extensive study of surface exchange coefficients has imperatively become important. Regional climate model simulations need to be carried out at CORDEX South Asia domain, which is a prescribed domain in climate modelling community to capture the significant features of South Asian summer monsoon and compare with in-situ observations. Further accurate 
estimation of RegCM model latent and sensible heat fluxes is of great importance, given their relevance to many physical processes in the Earth system. Through this study it is important to report the requirement of comparison of model and satellite soil moisture products with insitu observations especially during the JJAS monsoon season.

\section{Figures And Tables}

(a)
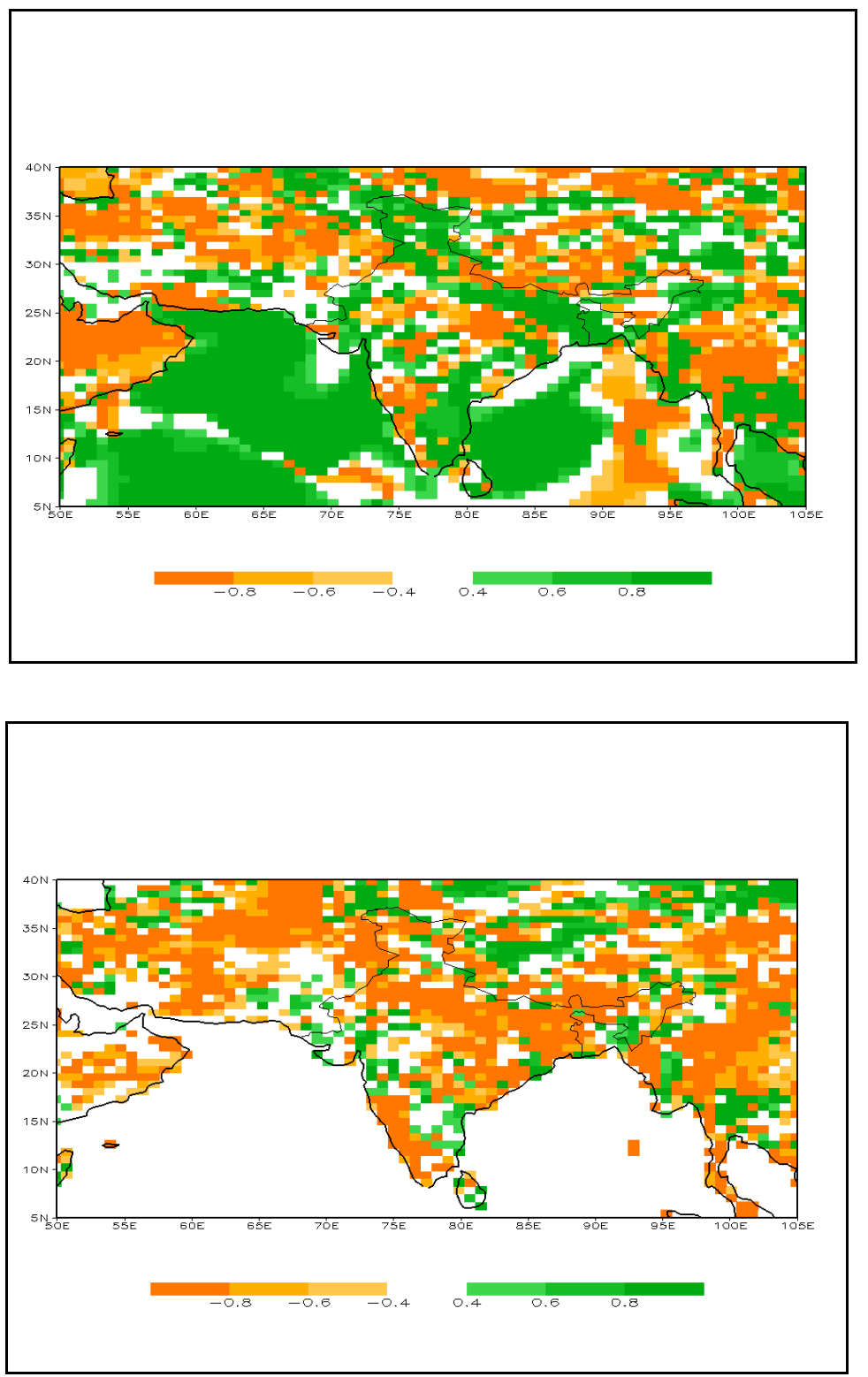

(b)

Figure 1 Model JJAS climatology of correlation, (a) $\rho(E, T)$ between evapotranspiration $(\mathrm{mm} /$ day) and temperature $(\mathrm{K})$, and (b) correlation, $\rho(\mathrm{SM}, \mathrm{T})$ between soil moisture $(\mathrm{mm})$ and temperature (K) (JJAS) from 1985 - 1995 
(a)

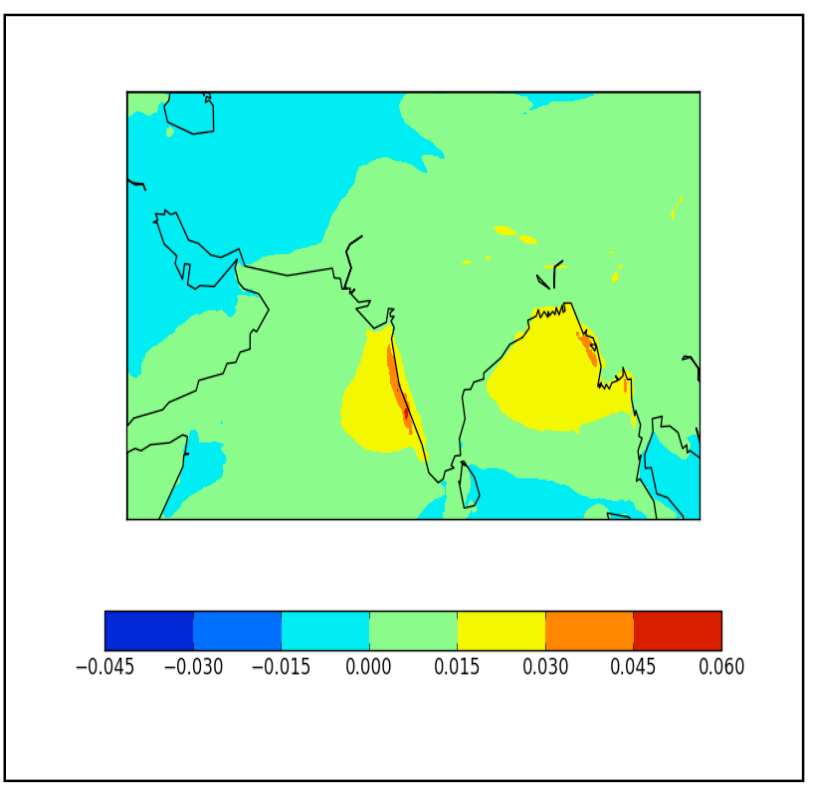

(b)

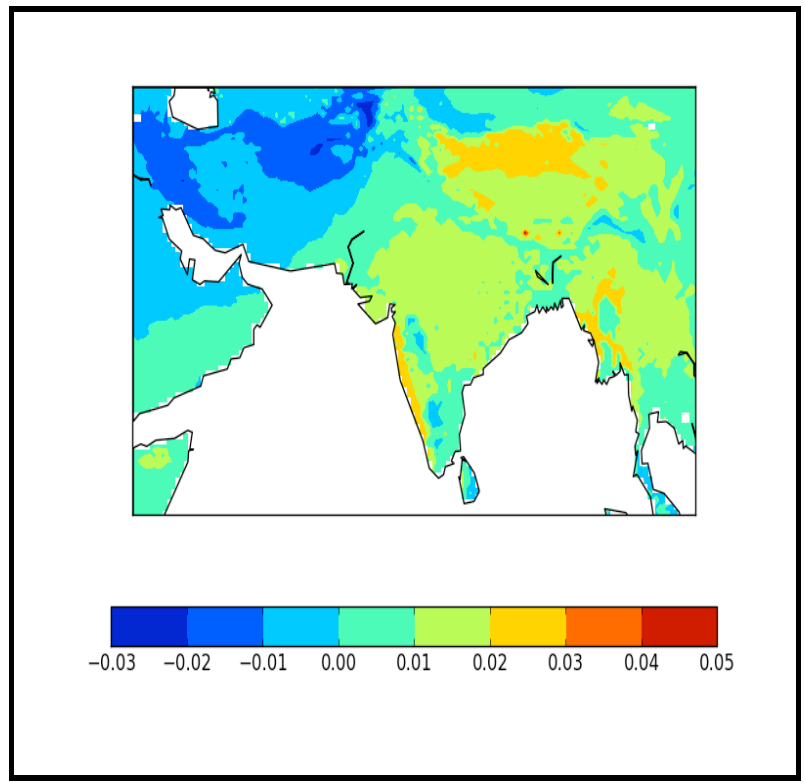

Figure 2. First empirical orthogonal function (EOF 1) for model (a) precipitation (b) soil moisture from 1985 - 1995 (JJAS).

\section{Acknowledgments}

We are thankful to Abdus Salam International Centre for Theoretical Physics, Trieste, Italy for making available the model codes of RegCM4.0 for this study. We also thank India Meteorological Department (IMD), and National Center for Environmental Prediction/ National Center for Atmospheric Research (NCEP/NCAR) for providing high-resolution rainfall and meteorological datasets for climate modeling and validation purpose. Also, special thanks to UV-CDAT/ CDAT team and developers (PCMDI) for free online UVCDAT package for computation of empirical orthogonal functions (http://ajdawson.github.io/eofs/userguide/overview.html).

\section{References}

\section{Journal Papers}

[1]. Seneviratne SI, Corti T, Davin EL, Hirschi M, Jaeger EB, Lehner I, Orlowsky B, Teuling AJ (2010) Soil moisture-climate interactions in a changing climate: A review. Earth Science Review, 99, 125-161, doi:10.1016/j.earscirev.2010.02.004

[2]. Lodh A., S. Jha, and R. Raghava, Impact of El Niño and La Niña on soil moisture precipitation feedback of Indian monsoon over Central India. Int. Arch. Photogramm. 
Remote Sens. Spatial Inf. Sci., XXXVIII-8/W20, 102-108, 2011 (www.int-archphotogramm-remote-sens-spatial-inf-sci.net/XXXVIII-8-W20/102/2011/doi:

10.5194/isprsarchives-XXXVIII-8-W20-102-2011)

[3]. Lodh and R. Raghava (2013), Soil moisture - precipitation feedback on Indian climatic zones in Indian summer monsoon regime (submitted) Vayumandal 2013

[4]. Koster, R. D., and Coauthors, 2004: Regions of strong coupling between soil moisture and precipitation. Science, 305, 1138-1140.

[5]. Christopher M. Taylor, Richard A. M. de Jeu, Françoise Guichard, Phil P. Harris \& Wouter A. Dorigo, 2012 Afternoon rain more likely over drier soils, Nature 489, 423426 (20 September 2012) doi:10.1038/nature11377

[6]. Giorgi, F., Cozzini, S., Elguindi, N., Giuliani, G., 2011. Regional Climatic Model RegCM User Manual.

[7]. Giorgi, et al., 2012. RegCM4: model description and preliminary tests over multiple CORDEX domains. Clim. Res. 52, 7-29.

[8]. Kiehl, J. T., J. J. Hack, G. B. Bonan, B. A. Boville, B. P. Breigleb, D. Williamson, and P. Rasch, 1996 Description of the NCAR community climate model (ccm3), Tech. Rep. NCAR/TN-420+STR, National Center for Atmospheric Research.

[9]. Holtslag, A. A. M., E. I. F. de Bruijn, and H. -L. Pan, A high-resolution air mass transformation model for short-range weather forecasting, Mon. Weather. Rev., 118, $1561-1575,1990$

[10]. Grell, G., Prognostic evaluation of assumptions used by cumulus parameterizations, Monthly Weather Review, 121, 764-787, 1993.

[11]. Fritsch, J.M., and C. F. Chappell, Numerical prediction of convectively driven mesoscale pressure systems. Part 1: Convective parameterization, J. Atmos. Sci., 37, 1722-1733, 1980.

[12]. Pal, Jeremy S., E. E. Small, and E. A. B. Eltahir, 2000 Simulation of regional-scale water and energy budgets: Representation of sub grid cloud and precipitation processes within RegCM, J. Geophysical Research Atmospheres, 105(D24), 29,579-29,594.

[13]. Zeng, X., M. Zhao, and R. E. Dickinson, Intercomparison of bulk aerodynamic algorithms for the computation of sea surface fluxes using toga coare and tao data, J. Climate, 11, 2628-2644, 1998

[14]. Kanamitsu, W. Ebisuzaki, J. Woollen, S-K Yang, J.J. Hnilo, M. Fiorino, and G. L. Potter. NCEP-DEO AMIP-II Reanalysis (R-2) 21631-1643, Nov 2002, Bulletin of the Atmos. Met. Soc.

[15]. Reynolds RW, Rayner NA, Smith TM, Stokes DC, Wang W (2002) An improved in situ and satellite SST analysis for climate. J Climate 15:1609-1625

[16]. Dickinson, R. E., A. Henderson-Sellers, and P. J. Kennedy, Biosphere-atmosphere transfer scheme (bats) version 1e as coupled to the NCAR community climate model, Tech. rep., National Center for Atmospheric Research, 1993.

[17]. Kulkami, A, Kripalani, R. H. and Singh, S. V 1992. 'Classification of summer monsoon rainfall patterns over India', International Journal of Climatology, 12, 269280.

[18]. Kripalani, R. H., Inamdar Sushama and Sontakke N.A. 1995. Rainfall variability over Bangladesh and Nepal: Comparison and Connections with features over India, Int. 1 Climatol., Vol. 16, 689-703 (1996).

[19]. Koster, R. D., and Coauthors, 2005: GLACE: The Global Land-Atmosphere Coupling Experiment. Part I: Overview, Journal of Hydrometeorology (American Meteorological Society), 590-610. 